\title{
Willingness to pay for flexibility at the workplace for people with diabetes and chronic disease: a discrete choice experiment in a population of workers in Denmark
}

\author{
Kristoffer Panduro Madsen ${ }^{* *}$ (D, Bryan Cleal ${ }^{1}$, Kasper Olesen ${ }^{1}$, Lise Hagelund ${ }^{2}$ and Ingrid Willaing ${ }^{1}$
}

\begin{abstract}
Background: The number of people of working age suffering from chronic disease is increasing. Chronic diseases such as diabetes can cause negative work-related consequences in the form of early retirement or absenteeism. Providing flexible workplace accommodations may enable the person with diabetes to retain their position in the labor market. However, the successfulness of such accommodations depends largely on the perceptions of those not suffering from diabetes. The purpose of this study was to examine preferences of a population of workers in Denmark for flexibility at the workplace, for people with diabetes and for people with chronic disease in general, measured as their willingness to pay (WTP).
\end{abstract}

Methods: Respondents were drawn from online panels and randomized to answer an online survey regarding flexibility at the workplace for people with diabetes or chronic disease in general. One thousand one hundred and three respondents were included in the analysis. Based on discrete choice experiments included in the survey, we analyzed WTP for five flexibility attributes: part-time, customizing job description, additional break with pay and time off for medical visits with and without pay. We further examined perceptions of the employer's responsibility to ensure workplace flexibility for five different specific chronic diseases including diabetes. Finally, we analyzed differences in WTP for flexibility across subgroups.

Results: Respondents' WTP was significantly higher for chronic disease in general compared to diabetes for the possibility of part-time ( $81 € /$ month vs. $47 € /$ month, $p<0.001)$ and customizing job description ( $58 € /$ month vs. $41 € /$ month, $p=0.018$ ) attributes, as well as for the overall average (49€/month vs. $36 € /$ month, $p=0.008)$. Ensuring workplace flexibility for patients with a specific chronic disease other than diabetes (cancer, heart disease, arthritis and COPD) was to a higher degree considered a responsibility of the employer. Average WTP for flexibility varied across subgroups, consistently yielding a larger amount for chronic disease in general.

Conclusions: The population examined in this study are willing to pay less for flexibility at the workplace for people with diabetes compared to people with chronic disease in general. This finding was evident in terms of specific flexibility attributes and on average across subgroups.

Keywords: Diabetes mellitus, Workplace, Flexibility, Willingness to pay, Discrete choice experiment

\footnotetext{
* Correspondence: kristoffer.panduro.madsen@regionh.dk

${ }^{1}$ Diabetes Management Research, Steno Diabetes Center Copenhagen, Niels

Steensens Vej 6, DK-2820 Gentofte, Denmark

Full list of author information is available at the end of the article
}

(c) The Author(s). 2019 Open Access This article is distributed under the terms of the Creative Commons Attribution 4.0 International License (http://creativecommons.org/licenses/by/4.0/), which permits unrestricted use, distribution, and reproduction in any medium, provided you give appropriate credit to the original author(s) and the source, provide a link to the Creative Commons license, and indicate if changes were made. The Creative Commons Public Domain Dedication waiver (http://creativecommons.org/publicdomain/zero/1.0/) applies to the data made available in this article, unless otherwise stated. 


\section{Background}

The global increase of people with diabetes and other chronic diseases is generating new challenges for health care systems across the globe [1]. With increased longevity, governments around the world have sought to increase the statutory age of retirement and thereby the average age of the workforce. One inference to be drawn from this is that the proportion of individuals in the workforce diagnosed with one or more chronic health conditions will also increase [2]. Given this, it is important to direct increased attention to what is required to enable people living with chronic conditions to retain their position in the labor market. Numerous studies have shown that having a chronic disease such as diabetes, cancer, heart disease, arthritis, and chronic obstructive pulmonary disease (COPD) increases the risk of work disability [3-7]. Indirect consequences of working while managing a chronic disease may also take their toll. People with a chronic disease are, for example, more prone to experience elevated levels of work-related fatigue [8], and this is a strong predictor of work disability $[9,10]$.

Flexibility at the workplace has been suggested as a means to avoid productivity loss due to early retirement and absenteeism [11, 12]. Studies have shown that providing flexible working conditions to employees can lead to increased engagement, motivation, job satisfaction and a better work-family balance $[13,14]$. Other research has shown that flexible working conditions lead to reduced stress and burnout and to better physical health $[15,16]$. Flexibility in the context of work can take many guises, but when considering the work-specific challenges confronted by people living with chronic disease, tailored accommodations which make the workplace a more amenable place can, potentially, play an important role in helping people remain productive at work $[12,17]$. The degree to which such accommodations are likely to be implemented and successful will, however, be partly determined by the extent to which they are recognized as effective and appropriate by those who do not suffer from chronic disease. At present, knowledge about preferences and attitudes regarding the perceived efficacy and suitability of workplace accommodations is sparse.

In recent years there has been an increased use of stated preference methods in which willingness to pay (WTP) is used to elicit health related preferences $[18,19]$. WTP is defined as the maximum amount of money a person is willing to pay for a certain good or service. In this study we investigated the WTP of a population of workers in Denmark without diabetes for flexibility at the workplace for people with diabetes, brought into relief by comparison with WTP for flexibility at work for people with chronic disease in general. Furthermore, we analyzed the opinion of the employer's responsibility to ensure flexible working conditions for people with cancer, heart disease, arthritis, COPD and diabetes. Finally, we analyzed WTP for flexibility at the workplace for diabetes compared to chronic disease in general across subgroups.

\section{Methods \\ Data collection}

This study is based on data $(n=1200)$ acquired in larger a survey conducted in Denmark in the spring of 2015 from March 24 to June 10. The survey was performed as an online survey and respondents were recruited by e-mail from existing online panels with more than 150,000 Danish panelists (http://www.userneeds.dk). Weights based on age, gender and geography were applied to reflect the demographic pattern of the working-age population. Inclusion criteria were age between 25 and 67 years, employed in a place of work with at least one colleague, and residence in Denmark. The overall focus of the larger survey was diabetes in work life and for this reason people with diabetes were oversampled in the recruitment process. Results from the larger study, including people with diabetes, have previously been published elsewhere [20]. For the purposes of this study, however, in which the primary focus are the preferences of a working population without diabetes in Denmark, people with diabetes were excluded from the analysis.

\section{Survey instrument}

The survey included items regarding participant demographics such as age, gender, education and employment status. The survey also included items regarding individuals' health status and a set of discrete choice experiments (DCEs) designed to measure participants' WTP. In a DCE, individuals are asked to choose between a set of hypothetical scenarios which vary across different attributes and levels, incorporating a hypothetical monetary attribute, making an analysis of WTP for each attribute possible [21]. This approach quantifies the respondents' preferences through their WTP, under the assumption that the chosen scenario represents their preferred option. We assessed WTP for flexibility at the workplace for five attributes; possibility of part-time, possibility of customizing job description, additional break with pay, and time off for medical visits and education with and without pay (Table 1). The underlying premise was that respondents were to imagine that the amount they were willing to pay would be subtracted from their monthly pay check after tax (see Additional file 1 for the exact wording used to introduce the DCEs). Upon initiation of the survey, we allocated $50 \%$ of the respondents to answer the DCEs with regards to people with diabetes and $50 \%$ with regards to people with chronic disease in general. In addition to the DCEs, the survey also contained questions regarding perceived degree of the employer's responsibility in ensuring flexibility at the 
Table 1 Work-related flexibility attributes at the workplace

\begin{tabular}{ll}
\hline Attribute & Level \\
\hline Possibility of part-time & Yes \\
Possibility of customizing job description & Yes \\
Additional break with pay & No \\
& Yes \\
Time off for medical visits and education & No \\
& Yes - with pay \\
& Yes - without pay \\
Reduction in monthly pay check after taxes & No \\
& DKK 50 / 6.6 $€^{\mathrm{a}}$ \\
& DKK 100 / 13.3 $€^{\mathrm{a}}$ \\
& DKK 200 / 26.6 $€^{\mathrm{a}}$ \\
& DKK 500 / 66.6 $€^{\mathrm{a}}$ \\
\hline
\end{tabular}

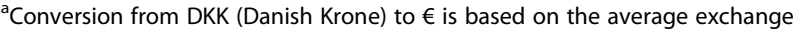
rate in 2015 of 7.45

workplace for people with cancer, heart disease, arthritis, COPD and diabetes.

\section{Design of discrete choice experiments}

The face validity of the attributes and levels used to design the DCEs was based on expert opinions and literature review. Initially these were tested at a diabetes clinic in Denmark with six people with diabetes. These individuals were subsequently interviewed about their opinions regarding the relevance of the attributes and levels and the extent to which they found the questionnaire to be usable and comprehensible. Finally, a pilot test among 92 individuals from online panels led to an increase in the levels of monthly pay reductions as they were initially set too low.

The attributes and levels in the DCEs could be combined in many ways. To reduce the number of questions to a manageable size, we used a standardized process in Ngene $^{\circ}$. The design practices used here are in line with the practices described in Johnson et al. [21]. Twenty-four DCE scenarios focused on work-related flexibility were generated (see Table 2 for an example of a scenario). The scenarios were divided into 4 groups and randomized into 4 different versions of the questionnaire. Thus, the individual respondents were presented with 6 scenarios regarding flexibility at the workplace for which their WTP for each preferred option could be obtained. Table 2 presents an example (see Additional file 2 for a complete 6-scenario combination) of one of the scenarios in which the respondents were asked if they preferred the combination of attributes in option A or option B while simultaneously considering the given WTP amount. Answering multiple scenarios permits estimation of a population-average WTP for each attribute. If respondents
Table 2 Example of a discrete choice experiment for workrelated flexibility

\begin{tabular}{lll}
\hline Attribute & Option A & Option B \\
\hline Possibility of part-time & No & Yes \\
Customizing job description & No & Yes \\
Additional break with pay & Yes & No \\
Time off for medical visits & Yes - the person & No \\
and education & can attend with pay & \\
Reduction in pay check & DKK 200 / 26.6 $€^{\text {a }}$ & DKK 100 / \\
after taxes per month & & $13.3 €^{\text {a }}$ \\
Which option do you prefer? & $\square$ & $\square$ \\
\hline
\end{tabular}

${ }^{a}$ Conversion from DKK (Danish Krone) to $€$ is based on the average exchange rate in 2015 of 7.45

reported that they did not understand the scenarios or gave conflicting responses, they were excluded from the analysis.

\section{Statistical analysis}

The discrete choice responses were analyzed using the conditional logit model using a procedure previously described $[18,20]$. We undertook a bootstrapping exercise using 10,000 iterations as recommended in Barker [22] to compute confidence intervals for the WTP estimates. To analyze differences in respondent characteristics, we used Pearson's Chi-squared test and Fisher's Exact test for categorical variables and Student's t-test for continuous variables. All $p$-values were two-sided and values $<0.05$ were considered statistically significant. All statistical analyses were performed using SAS version 9.4.

\section{Results}

\section{Respondents}

In total, 1139 respondents met the inclusion criteria and completed the questionnaire relevant for this study. Thirty-six respondents were excluded because they reported not understanding the DCE scenarios rendering a study population of 1103 participants consisting of 534 (48\%) women and 569 (52\%) men with an average age of 45 . There were no statistically significant differences in respondent characteristics between the group asked about diabetes and those asked about chronic disease in general (Table 3).

\section{Preferences for flexibility at the workplace}

There was a WTP for flexibility at the workplace both for diabetes and chronic disease in general, with the latter having a higher WTP across all attributes. WTP was significantly higher in relation to chronic disease in general compared to diabetes for the Possibility of part-time $(p<0.001)$ and the Customizing job description $(p=0.018)$ attributes (Fig. 1). Respondents asked about flexible working conditions for diabetes were willing to pay $47 €$ per month [CI (95\% confidence 
Table 3 Respondent characteristics

\begin{tabular}{|c|c|c|c|}
\hline \multirow[t]{2}{*}{$N$} & $\begin{array}{l}\text { Respondents } \\
\text { asked about } \\
\text { diabetes (\%) }\end{array}$ & $\begin{array}{l}\text { Respondents asked } \\
\text { about chronic } \\
\text { diseases (\%) }\end{array}$ & $\begin{array}{l}\text { Difference } \\
P \text {-value }\end{array}$ \\
\hline & 540 & 563 & \\
\hline Men & $272(50)$ & 297 (53) & \\
\hline Women & $268(50)$ & $266(47)$ & 0.429 \\
\hline Age (average) & $46(S D=10.38)$ & $45(S D=10.43)$ & 0.450 \\
\hline $\begin{array}{l}\text { Full-time } \\
\text { employment }\end{array}$ & $515(95)$ & $541(96)$ & \\
\hline $\begin{array}{l}\text { Part-time } \\
\text { employment }\end{array}$ & $25(5)$ & $22(4)$ & 0.553 \\
\hline Public sector & $214(40)$ & $226(40)$ & \\
\hline Private sector & $326(60)$ & $337(60)$ & 0.862 \\
\hline $\begin{array}{l}\text { More than } \\
3 \text { years of further } \\
\text { education }\end{array}$ & $303(56)$ & $315(56)$ & \\
\hline $\begin{array}{l}\text { Less than } 3 \text { years } \\
\text { of further } \\
\text { education }\end{array}$ & $237(44)$ & $248(44)$ & 0.957 \\
\hline $\begin{array}{l}\text { Relatives or } \\
\text { friends with } \\
\text { diabetes }\end{array}$ & $205(38)$ & $184(33)$ & \\
\hline $\begin{array}{l}\text { No relatives or } \\
\text { friends with } \\
\text { diabetes }\end{array}$ & $335(62)$ & $379(67)$ & 0.067 \\
\hline Arthritis & $30(6)$ & $23(4)$ & 0.254 \\
\hline Asthma & $18(3)$ & $23(4)$ & 0.509 \\
\hline Back pain & $19(4)$ & $27(5)$ & 0.289 \\
\hline Depression & $22(4)$ & $24(4)$ & 0.875 \\
\hline $\begin{array}{l}\text { Decreased } \\
\text { hearing }\end{array}$ & $12(2)$ & $11(2)$ & 0.755 \\
\hline Migraine & $29(5)$ & $23(4)$ & 0.314 \\
\hline $\begin{array}{l}\text { Other long-term } \\
\text { disease }\end{array}$ & $52(10)$ & $54(10)$ & 0.983 \\
\hline
\end{tabular}

Reported chronic conditions had been treated within the past year upon completion of the survey. Differences tested with Chi-squared tests and Student's t-test for categorical and continuous outcomes, respectively $S D$ Standard deviation

interval): $39-57 €]$ for the possibility of part-time, while respondents asked about flexible working conditions for chronic disease in general were willing to pay $81 €$ per month [CI: $68-96 €]$. With regards to the possibility of customizing job description, respondents asked about diabetes were willing to pay $41 €$ per month [CI: 33-49 $€$ ] and respondents asked about chronic disease in general were willing to pay $58 €$ per month [CI: $47-70$ $€$. The difference in average WTP across all attributes was also statistically significant between the two groups $(p=0.008)$ with $36 €$ per month [CI: $28-45 €$ ] for people asked about diabetes compared to $49 €$ per month [CI: $28-60 €]$ for people asked about chronic disease in general.
Employer responsibility for flexible working conditions When asked about employer responsibility for flexible working conditions for specific chronic diseases, there were clear differences in opinions regarding cancer, heart disease, arthritis COPD and diabetes, respectively (Fig. 2). When asked about cancer, 73\% [CI: 70-75\%] thought it was to a large or very large degree the employer's responsibility to ensure flexible working conditions. In the case of heart disease and arthritis, 56\% [CI: 53-59\%] and 54\% [CI: 51-57\%], respectively, found the employer to be responsible for ensuring flexible working conditions. This was the case for $43 \%$ of respondents [CI: $40-46 \%$ ] regarding COPD and for 33\% [CI: 30-35\%] of respondents regarding diabetes.

\section{Differences in flexibility preferences across subgroups}

Table 4 shows the average WTP for flexibility across different subgroups. There were statistically significant differences in WTP among women $(p=0.012)$, people aged 25-49 years $(p=0.042)$, people with less than 3 years of further education $(p=0.012)$, people who do not have a relative with diabetes $(p=0.028)$ and people who themselves had been treated for a chronic disease other than diabetes within the last year $(p=0.012)$.

People who answered that it to a large or very large degree was the employer's responsibility to ensure flexible working conditions for all the specified chronic diseases had no difference in WTP values for diabetes and chronic disease in general. People who answered that it was not the employer's responsibility to ensure flexible working conditions for at least one of the chronic diseases were willing to pay more for flexible working conditions for people with chronic disease in general than for people with diabetes $(p<0.001)$.

\section{Discussion}

The population examined in this study is willing to pay more for flexibility at the workplace for people with a chronic disease in general than they are prepared to pay for people with diabetes. The difference in WTP was statistically significant for the "Possibility of part-time" and "Customizing job description" attributes, as well as for the overall average. There were also statistically significant differences in WTP between diabetes and chronic disease in general across subgroups, all of which were found to be higher for chronic disease. This was evident for the subgroups: female, 25-49 years, less than 3 years of further education, relatives or friends with diabetes, treated for a chronic disease within the last year, and the employer not being responsible for flexible working conditions. Our results further indicate that people perceive diabetes, in relative terms, to be of least importance when considering the extent to which employers should ensure flexible work conditions for 


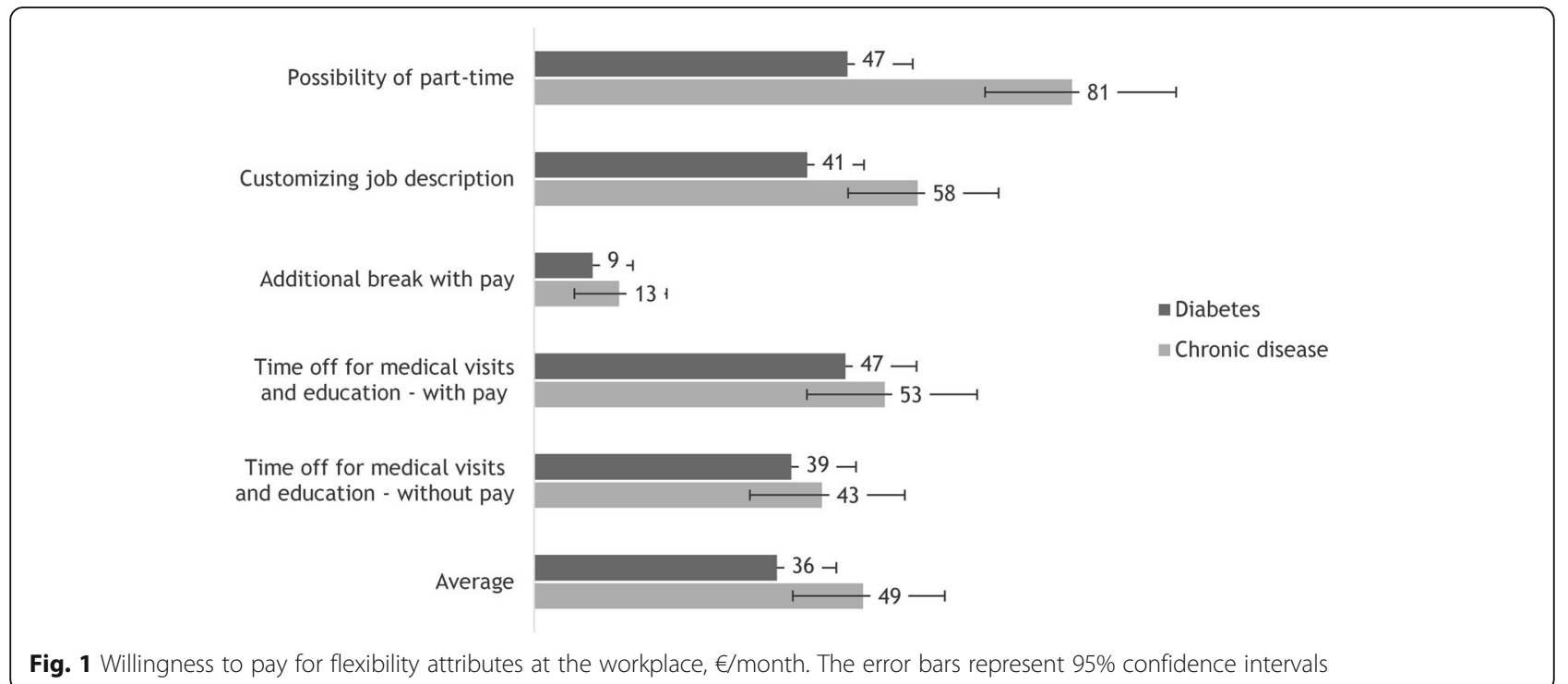

people with chronic diseases. Although certain flexibility attributes and subgroup analyses did not reach statistical significance, possibly due to sample size, the estimated WTP amounts still indicate an empirically relevant WTP in both groups.

The differences in WTP and opinions regarding employer responsibility may be explained by the perceived severity of the diseases in question. Previous studies have shown that diabetes is perceived as the least severe disease in comparison with heart disease, cancer and stroke [23-25]. Furthermore, it has been shown that people view diabetes as a relatively controllable disease as compared to cancer for example [23, 24]. Other research reveals that concern about developing diabetes is relatively low for both women, for whom concerns about breast cancer and heart disease figure more prominently, and men, among whom heart disease and prostate cancer give cause for greatest concern [25]. Likewise, it has also been demonstrated that people have a tendency to underestimate their risk of developing type 2 diabetes [26]. Viewed in light of the existing literature, our results suggest that people of working age do not regard diabetes as a disease that requires as much flexibility or accommodation in the workplace as other chronic diseases, at least in terms of their WTP. This is indicative of a prevailing perception about diabetes as a condition which is essentially manageable and thus not requiring the same level of flexibility or accommodation in the context of work as, for instance, cancer and heart disease. This suggests a potential need for dissemination of knowledge on how to support people with diabetes to be able to reconcile diabetes and work life and to enable people with diabetes to stay in the labor market without limitations brought on by their condition.

Our analysis of WTP for diabetes and chronic disease in general across subgroups revealed that female participants were willing to pay significantly more for chronic disease in general compared to diabetes, while no

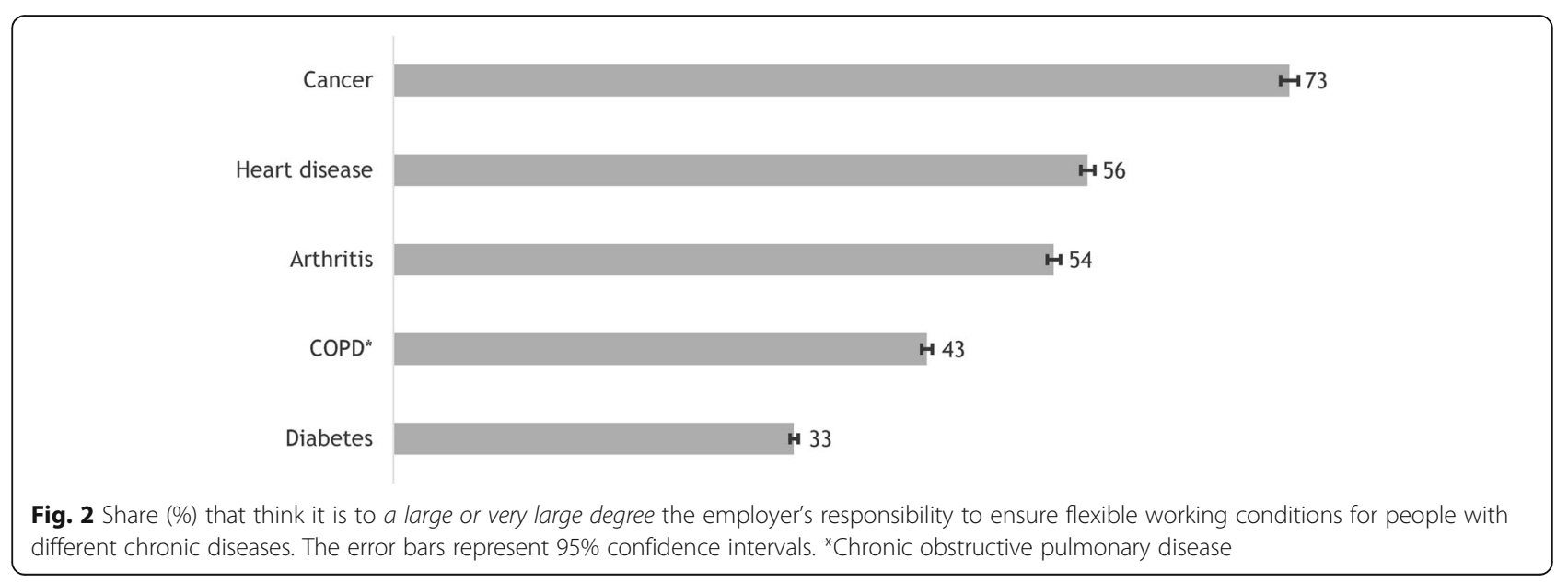


Table 4 Willingness to pay for flexibility at the workplace for people with diabetes and chronic disease in general among subgroups, €/month deducted from pay-check after taxes

\begin{tabular}{|c|c|c|c|c|c|}
\hline & $\begin{array}{l}\mathrm{N}(\%) \\
\text { Diabetes }\end{array}$ & $\begin{array}{l}\mathrm{N}(\%) \\
\text { Chronic disease }\end{array}$ & $\begin{array}{l}\text { WTP } \\
\text { Diabetes }(€)\end{array}$ & $\begin{array}{l}\text { WTP } \\
\text { Chronic disease }(€)\end{array}$ & $\begin{array}{l}\text { Difference } \\
P \text {-value }\end{array}$ \\
\hline Average & 540 & 563 & 36 & 49 & $0.008^{*}$ \\
\hline \multicolumn{6}{|l|}{ Gender } \\
\hline Male & $272(50)$ & $297(53)$ & 44 & 55 & 0.248 \\
\hline Female & $268(50)$ & $266(47)$ & 32 & 46 & $0.012^{*}$ \\
\hline \multicolumn{6}{|l|}{ Age } \\
\hline $25-49$ years & $316(59)$ & $338(60)$ & 32 & 43 & $0.042^{*}$ \\
\hline 50-67 years & $224(42)$ & $225(40)$ & 45 & 69 & 0.080 \\
\hline \multicolumn{6}{|l|}{ Education } \\
\hline Less than 3 years of further education & $237(44)$ & $248(44)$ & 34 & 54 & $0.012^{*}$ \\
\hline More than 3 years of further education & $303(56)$ & $315(56)$ & 39 & 47 & 0.224 \\
\hline \multicolumn{6}{|l|}{ Relative with diabetes } \\
\hline Do not have relatives or friends with diabetes & $335(62)$ & $379(67)$ & 39 & 55 & $0.028^{*}$ \\
\hline Have relatives or friends with diabetes & $205(38)$ & $184(33)$ & 34 & 40 & 0.352 \\
\hline \multicolumn{6}{|l|}{ Morbidity $^{a}$} \\
\hline Not treated for chronic disease within the last year & $381(71)$ & $412(73)$ & 39 & 48 & 0.140 \\
\hline Treated for chronic disease within the last year & $159(29)$ & $151(27)$ & 33 & 57 & $0.012^{*}$ \\
\hline \multicolumn{6}{|l|}{ Employer responsibility ${ }^{b}$} \\
\hline Employer responsible for flexible work conditions & $124(23)$ & $112(20)$ & 59 & 76 & 0.436 \\
\hline Employer not responsible for flexible work conditions & $416(77)$ & $451(80)$ & 29 & 46 & $<0.001^{*}$ \\
\hline
\end{tabular}

'Diseases - arthritis, asthma, atherosclerosis, back disease, cancer, COPD, depression, decreased hearing, migraine, stroke and other long-term disease ${ }^{b}$ Employer is to a large or very large degree responsible for ensuring flexible working conditions for diabetes, COPD, cancer, heart disease and arthritis. Differences tested with Chi-squared tests

*Statistically significant at an alpha of 0.05

differences were found in the male subgroup. Being in the younger subgroup and being in the subgroup with a lower level of education also yielded significantly higher WTP values for chronic disease in general compared to diabetes. One potential reason for these observations is the relationship between the respective subgroups and their mean income. All three subgroups, at least in Denmark, are known to have a lower income compared to their counterparts (males, older age group, more than 3 years of further education) [27, 28]. Previous research has shown that income is positively correlated with WTP [29-31]. As such, the lower WTP for diabetes compared to chronic disease in these subgroups may reflect a certain difference in ability to pay or at least a different prioritization of disposable income. This inference is also supported by the fact that all three subgroups had a lower WTP value for both diabetes and chronic disease compared to their counterparts, except in the case of chronic disease in the less than 3 years of further education subgroup. WTP in different subgroups of the population may also be partly determined by risk of developing a chronic disease, e.g. indicated by the markedly higher WTP for both diabetes and chronic disease in general of the older age group compared to the younger.

The subgroup analysis further showed that people who do not have relatives or friends with diabetes are willing to pay significantly more for chronic disease in general compared to diabetes, whereas for those with a relative or friend with diabetes there was no statistically significant difference. This finding indicates that respondents with first-hand knowledge of diabetes are more inclined to recognize the need for workplace accommodations and less inclined to view diabetes as of less importance than chronic disease in general. However, the WTP value for diabetes in this subgroup was still lower than for respondents without a friend or relative with the condition. The relatively low WTP among this group may initially seem counter-intuitive, suggesting a perception of diabetes as a relatively manageable disease among people who know someone with the condition. At the same time, in the context of the Danish welfare state, it may also reflect the fact that people who are familiar with diabetes feel that workplace accommodations should be covered by existing legislation regarding flexibility at the workplace. 
The respondents who had themselves been treated for a chronic disease within the past year reported a significantly higher WTP for chronic disease in general compared to diabetes, while not having been treated resulted in no statistically significant difference. While not a surprising finding, this result indicates that people who have first-hand experience with chronic disease value flexibility at the workplace higher for chronic disease in general than for diabetes and, since this outcome is to be expected, supports the validity of the discrete choice methodology as capable and sensitive enough to ascertain actual, true preferences.

The results we present indicate that diabetes has a relatively modest ranking as a condition for which flexibility and accommodation at work are perceived to be justified. Public perceptions about diabetes in this context do not, therefore, tally well with what is known about the demands and consequences of the condition in the context of work life [32]. Numerous studies have demonstrated that a diagnosis with diabetes impacts negatively on a range of labor market outcomes e.g. early retirement [33], productivity [34], absenteeism [35] and income levels [36]. The findings we present here indicate that the working population is willing to pay for flexible working conditions for people with chronic disease in general as well as for people with diabetes. However, diabetes was across all our results consistently rated as a disease requiring less flexibility at the workplace compared to chronic disease in general, indicating a lack of knowledge and understanding about the actual scale of the problem of having diabetes in the context of work life.

\section{Strengths and limitations}

To our knowledge, this is the first study comparing WTP for flexibility at the workplace for people with diabetes and for people with chronic disease in general. Strengths of this study include the large study population and high response efficiency. Furthermore, there were no statistically significant differences in demographic or chronic disease variables between the group asked about diabetes and the group asked about chronic disease in general, limiting bias arising from heterogeneity between groups. A noteworthy strength of the DCEs used in this study is the ability to concretize the rather abstract question of how much one is willing to pay for a hypothetical attribute by obliging the respondent to choose between predefined options. Another strength of the DCE is the balanced and orthogonal design resulting in a perfectly efficient design [21].

Although the DCE has many advantages, there may be some methodological limitations. DCEs may be cognitively challenging for some people, in part due to possible fatigue from the large number of questions and also due to respondents' evaluations regarding the hypothetical context of the experiment [21]. Our response efficiency was, however, high with only 36 respondents excluded due to not understanding the DCE scenarios, indicating that the experiments were meaningful to the participants. Respondents with diabetes were excluded in this study. This may have resulted in slightly overestimated WTP values for flexible accommodations for people with diabetes at work as a previous study, surprisingly, showed relatively lower WTP for flexibility accommodations at work for people with diabetes among people with diabetes themselves [20]. Thus, the difference in WTP for people with diabetes and other chronic diseases may be even bigger than this study suggests. Furthermore, there may be issues of generalizability as it may only be a certain selected group of the general population (e.g., blue-collar workers) who participate in online surveys.

We recognize that, in seeking to set perceptions about diabetes into relief, we have compared diabetes to a number of chronic conditions with which it is often comorbid. The relative influence of diabetes specific morbidity and comorbidity in relation to the labor market outcomes of people with diabetes is, however, an important point of focus and one which research has only recently begun to address [37]. In contrast to public perceptions about the relative severity of diabetes in the context of work life, epidemiological evidence indicates a profound problem impacting both individuals and society at large. There is, moreover, the threat that diabetes will become more prevalent in the working population in the future if population ageing and lifestyle trends continue their current course. Now may be the time to take seriously the challenges that people with diabetes face in their work-life context.

\section{Conclusions}

WTP for flexibility at the workplace was significantly higher for people with chronic disease in general compared to people with diabetes. Furthermore, employers' responsibility for workplace flexibility in relation to diabetes was ranked lower than it was for cancer, heart disease, arthritis and COPD. WTP differed considerably across subgroups, indicating a higher WTP for chronic disease in general across all groups. These findings suggest a perceptual lacuna regarding the actual challenges faced by the individuals with diabetes in the context of work life and, moreover, to the challenges faced by society at large in terms of increasing indirect costs associated with diabetes. This suggests a potential need for dissemination of knowledge on how to support people with diabetes to be able to reconcile diabetes and work life and to enable people with diabetes to stay within the 


\author{
labor market without limitations brought on by their \\ condition.
}

\section{Additional files}

Additional file 1: Introduction to discrete choice experiments. The exact wording shown to participants prior to the discrete choice experiments. (PDF $205 \mathrm{~kb}$ )

Additional file 2: Discrete choice experiments. Example of a 6-scenario DCE combination shown to participants. (PDF $104 \mathrm{~kb}$ )

\section{Abbreviations}

COPD: Chronic obstructive pulmonary disease; DCE: Discrete choice experiment; WTP: Willingness to pay

\section{Acknowledgements}

Not applicable.

\section{Funding}

This study received no funding resources.

\section{Availability of data and materials}

The datasets generated and/or analyzed during the current study cannot be made publicly available according to the Danish law of personal data protection, allowing only the person responsible for the data management to manage data after approval from the Danish Protection Agency. However, data inquiries or further suggestions for analyses can be made to the author KPM.

\section{Authors' contributions}

IW, BC and LH were responsible for the initial idea and survey design. KO was responsible for data-collection. LH was responsible for the analyses of the discrete choice experiments and the initial drafting of findings. IW, BC, $\mathrm{KO}$ and KPM were responsible for interpretation of findings. KPM drafted the manuscript. All authors commented and contributed with revisions and all authors read and approved the final manuscript.

\section{Ethics approval and consent to participate}

The study protocol was submitted to the Danish Ethical Committee (case number: H-15000641). Protocols for survey studies are exempted from ethical approval in Denmark, but approval from the Danish Protection Agency was required and subsequently obtained (identification number: 2007-58-0015). The study was performed in accordance with the Declaration of Helsinki and written informed consent was obtained from participants.

\section{Consent for publication}

Not applicable.

\section{Competing interests}

The authors declare that they have no competing interests.

\section{Publisher's Note}

Springer Nature remains neutral with regard to jurisdictional claims in published maps and institutional affiliations.

\section{Author details}

1Diabetes Management Research, Steno Diabetes Center Copenhagen, Niels Steensens Vej 6, DK-2820 Gentofte, Denmark. ${ }^{2}$ Incentive, Holte, Denmark.

Received: 25 April 2019 Accepted: 29 April 2019

Published online: 16 May 2019

\section{References}

1. Murray CJ, Vos T, Lozano R, Naghavi M, Flaxman AD, Michaud C, et al. Disability-adjusted life years (DALYs) for 291 diseases and injuries in 21 regions, 1990-2010: a systematic analysis for the global burden of disease study 2010. Lancet. 2012;380(9859):2197-223.

2. Maestas N, Zissimopoulos J. How longer work lives ease the crunch of population aging. J Econ Perspect. 2010;24(1):139-60.
3. Short PF, Vasey JJ, Belue R. Work disability associated with cancer survivorship and other chronic conditions. Psychooncology. 2008;17(1):91-7.

4. Yen L, McRae I, Jeon YH, Essue B, Herath P. The impact of chronic illness on workforce participation and the need for assistance with household tasks and personal care by older Australians. Health Soc Care Community. 2011;19(5):485-94.

5. Breton MC, Guenette L, Amiche MA, Kayibanda JF, Gregoire JP, Moisan J. Burden of diabetes on the ability to work: a systematic review. Diabetes Care. 2013:36(3):740-9.

6. Von Korff M, Katon W, Lin EHB, Simon G, Ciechnaowski P, Ludman E, et al. Work disability among individuals with diabetes. Diabetes Care. 2005; 28:1326-32.

7. Ervasti J, Virtanen M, Pentti J, Lallukka T, Tinghog P, Kjeldgard L, et al. Work disability before and after diabetes diagnosis: a nationwide populationbased register study in Sweden. Am J Public Health. 2015;105(6):e22-9.

8. Donders NC, Roskes K, van der Gulden JW. Fatigue, emotional exhaustion and perceived health complaints associated with work-related characteristics in employees with and without chronic diseases. Int Arch Occup Environ Health. 2007:80(7):577-87.

9. Van Amelsvoort LGPM, Kant IJ, Beurskens AJHM, Schröer CAP, Swaen GMH. Fatigue as a predictor of work disability. J Occup Environ Med. 2002;59:712-3.

10. Varekamp I, Van Dijk FJ. Workplace problems and solutions for employees with chronic diseases. Occup Med (Lond). 2010;60(4):287-93.

11. Kossek EE, Hammer LB, Thompson RJ, Burke LB. Leveraging workplace flexibility for engagement and productivity. Society for human resource management; 2014

12. Detaille SI, Haafkens JA, Hoekstra JB, van Dijk FJ. What employees with diabetes mellitus need to cope at work: views of employees and health professionals. Patient Educ Couns. 2006:64(1-3):183-90.

13. WorldatWork. Survey on workplace flexibility 2013. 2013.

14. Hayman JR. Flexible work arrangements: exploring the linkages between perceived usability of flexible work schedules and work/life balance. Community Work Fam. 2009:12(3):327-38.

15. Butler AB, Grzywacz JG, Ettner SL, Liu B. Workplace flexibility, self-reported health, and health care utilization. Work Stress. 2009:23(1):45-59.

16. Grzywacz JG, Carlson DS, Shulkin S. Schedule flexibility and stress: linking formal flexible arrangements and perceived flexibility to employee health. Community Work Fam. 2008;11(2):199-214.

17. Detaille SI, Haafkens JA, van Dijk FJ. What employees with rheumatoid arthritis, diabetes mellitus and hearing loss need to cope at work. Scand J Work Environ Health. 2003;29(2):134-42.

18. Schiøtz M, Bogelund M, Almdal T, Willaing I. Discrete choice as a method for exploring education preferences in a Danish population of patients with type 2 diabetes. Patient Educ Couns. 2012;87(2):217-25.

19. Janssen EM, Longo DR, Bardsley JK, Bridges JFP. Education and patient preferences for treating type 2 diabetes: a stratified discrete-choice experiment. Patient Prefer Adherence. 2017;11:1729-36.

20. Nexo MA, Cleal B, Hagelund L, Willaing I, Olesen K. Willingness to pay for flexible working conditions of people with type 2 diabetes: discrete choice experiments. BMC Public Health. 2017:17(1):938.

21. Johnson FR, Lancsar E, Marshall D, Kilambi V, Muhlbacher A, Regier DA, et al. Constructing experimental designs for discrete-choice experiments: report of the ISPOR conjoint analysis experimental design good research practices task force. Value Health. 2013;16(1):3-13.

22. Barker N. A practical introduction to the bootstrap using the SAS system. Wallingford: Oxford Pharmaceutical Sciences; 2005. Report No: PK02

23. Wang C, O'Neill SM, Rothrock N, Gramling R, Sen A, Acheson LS, et al. Comparison of risk perceptions and beliefs across common chronic diseases. Prev Med. 2009:48(2):197-202.

24. Walter FM, Emery J. Perceptions of family history across common diseases: a qualitative study in primary care. Fam Pract. 2006:23(4):472-80.

25. DiLorenzo TA, Schnur J, Montgomery GH, Erblich J, Winkel G, Bovbjerg DH. A model of disease-specific worry in heritable disease: the influence of family history, perceived risk and worry about other illnesses. J Behav Med. 2006:29(1):37-49.

26. Pierce $M$, Harding $D$, Ridout $D$, Keen $H$, Bradley $C$. Risk and prevention of type II diabetes: offspring's views. Br J Gen Pract. 2001:51(464):194-9.

27. Cleal B, Panton UH, Willaing I, Holt RIG. Relative changes in earned income five years after diagnosis with diabetes: a register based study 1996-2012. J Diabetes Complicat. 2017;31(10):1506-14. 
28. Sortso C, Green A, Jensen PB, Emneus M. Societal costs of diabetes mellitus in Denmark. Diabet Med. 2016;33(7):877-85.

29. Lang HC. Willingness to pay for lung cancer treatment. Value Health. 2010:13(6):743-9.

30. Ramsey SD, Sullivan SD, Psaty BM, Patrick DL. Willingness to pay for antihypertensive care: evidence from a staff-model HMO. Soc Sci Med. 1997:44(12):1911-7.

31. Jonas $D E$, Russell $L B$, Chou J, Pignone M. Willingness-to-pay to avoid the time spent and discomfort associated with screening colonoscopy. Health Econ. 2010;19(10):1193-211.

32. Ruston A, Smith A, Fernando B. Diabetes in the workplace - diabetic's perceptions and experiences of managing their disease at work: a qualitative study. BMC Public Health. 2013;13:386.

33. Cleal B, Poulsen K, Hannerz H, Andersen LL. A prospective study of occupational status and disability retirement among employees with diabetes in Denmark. Eur J Pub Health. 2015;25(4):617-9.

34. Tunceli K, Bradley CJ, Nerenz D, Williams LK, Pladevall M, Elston Lafata J. The impact of diabetes on employment and work productivity. Diabetes Care. 2005;28(11):2662-7.

35. Tunceli K, Bradley CJ, Lafata JE, Pladevall M, Divine GW, Goodman AC, et al. Glycemic control and absenteeism among individuals with diabetes. Diabetes Care. 2007:30(5):1283-5.

36. Valdmanis V, Smith DW, Page MR. Productivity and economic burden associated with diabetes. Am J Public Health. 2001;91 (1):129-30.

37. Ervasti J, Virtanen M, Lallukka T, Pentti J, Kjeldgard L, Mittendorfer-Rutz E, et al. Contribution of comorbid conditions to the association between diabetes and disability pensions: a population-based nationwide cohort study. Scand J Work Environ Health. 2016;42(3):209-16.

Ready to submit your research? Choose BMC and benefit from:

- fast, convenient online submission

- thorough peer review by experienced researchers in your field

- rapid publication on acceptance

- support for research data, including large and complex data types

- gold Open Access which fosters wider collaboration and increased citations

- maximum visibility for your research: over $100 \mathrm{M}$ website views per year

At $\mathrm{BMC}$, research is always in progress.

Learn more biomedcentral.com/submissions 